\title{
Photo-degradation of the methyl blue: Optimization through response surface methodology using rotatable center composite design
}

\author{
Munawar Iqbal $^{1^{*}}$, Ijaz Ahmad Bhatti ${ }^{1^{*}}$ and Iftikhar Ahmad ${ }^{2}$ \\ ${ }^{I}$ Department of Chemistry and Biochemistry, University of Agriculture, Faisalabad-38040, Pakistan, \\ ${ }^{2}$ Department of Mathematical Sciences, Göteborg University, SE-41296, Göteborg, Sweden \\ *Corresponding authorE-mail: ijazchem@yahoo.com; bosalvee@yahoo.com
}

\begin{abstract}
Advanced oxidation processes (AOPs) generate in situ active hydroxyl radicals which allowed the destruction of polluting agents through mineralization. The suitable experimental design allows adjustment of factor levels to obtain an optimal response in experimental analysis. Rotatable Center Composite design and multivariate analysis were used for the optimization of the removal of methyl blue from aqueous solution, using UV (254 nm) radiation source and hydrogen peroxide as an oxidant. A factorial design $\left(2^{\mathrm{n}}\right)$ with repeated central and axial points was used to obtain the best experimental condition to efficiently remove the dye from aqueous solution and initial dye concentration, 50- 150 ppm and hydrogen peroxide 0.05- $5.95 \%$ was used as experimental variables. At optimum level up to $96.5 \%$ dye removal was recorded. Dye degradation followed the first order kinetics and dissolved oxygen and $\mathrm{pH}$ of the dye aqueous solution were found strongly correlated with the dye degradation.
\end{abstract}

Keywords: Advanced oxidation process, degradation, methyl blue, response surface methodology

\section{Introduction}

Methyl blue (C.I. 42780) belongs to triaminotriphenylmethane dyes. Methyl blue and aniline blue are so similar that both dyes are given same color index name "Acid blue 93" (Fig. 1). They are widely used as antiseptic dyes in polychrome staining methods and have applications in histological and microbiological staining solutions [1-2]. Before present study, methyl blue has been used as a model to study the effect of various catalysts on photo-degradation of dyes [3-4].

Wastewater containing dye is very difficult to treat by conventional methods due to their non-biodegradable and complex nature. Various physic-chemical and biological methods have been used in order to degrade the dyes present in wastewater [5-9]. These methods are efficient, however, the major constraints are the secondary pollution problem such as sludge and polluting agent transformation form one phase to another phase. Therefore, attention has to be focused on techniques that lead to the complete degradation of pollutants [10].

The AOPs techniques are attractive alternatives, able to mineralize organic contaminants and destruct the organic pollutants from wastewater rather transferring into solid phase medium. Processes involving the use of UV radiation and $\mathrm{H}_{2} \mathrm{O}_{2}$ are characterized by the generation of hydroxyl radicals in situ, which are short lived, but highly reactive chemical species and react non-selectively with organic matter present in medium. These radicals can oxidize organic compounds producing organic radicals, which are highly reactive and can undergo further oxidation. The possible reactions, which occur during $\mathrm{UV} / \mathrm{H}_{2} \mathrm{O}_{2}$ process, are hydrogen abstraction, electrophilic addition and electron transfer reaction and the final products are $\mathrm{H}_{2} \mathrm{O}, \mathrm{CO}_{2}$ and low molecular weight aliphatic acids and resultantly improve the water quality parameter [11-17].

The UV irradiation in the presence of hydrogen peroxide $\left(\mathrm{H}_{2} \mathrm{O}_{2}\right)$ is a very promising AOP technique (200-280 nm) which leads to disassociation of $\mathrm{H}_{2} \mathrm{O}_{2}$ and resultantly system generates hydroxyl radicals ('OH), highly powerful oxidizing species, produce organic radicals $\left(\mathrm{R}^{*}\right)$ and resultantly chain reaction is stared [8, 10, 18-19]. Regarding the importance of AOPs, UV/ $\mathrm{H}_{2} \mathrm{O}_{2}$ system was used for degradation of methyl blue and optimized the variable (dye concentration and $\mathrm{H}_{2} \mathrm{O}_{2}$ percentage) for maximum dye removal. The effect of AOP treatment system on $\mathrm{pH}$ and DO was also evaluated and compared with true effluent form textile industry. 


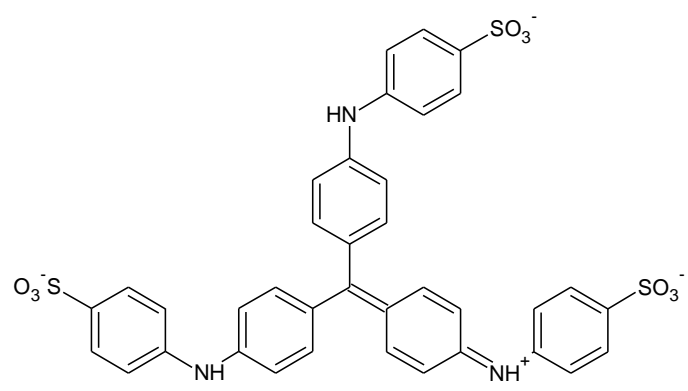

Fig. 1: Structure of methyl blue

\section{Material and methods}

\subsection{Experimental design}

Initially a $2^{\mathrm{n}}$ factorial design with $\mathrm{n}=2$ was used with only 4 runs. $(-1,-1),(1,-1),(-1,1)$ and $(1,1)$. However, in this form all of the model parameters $(\beta)$ could not be estimated. Central Composite design is the best solution, since it gives almost as much information as a multilevel factorial [20]. The number of runs was increased by adding central points and axial points and used for estimating second order surface design Box and Hunter (1957). For axial points, $\alpha=\left(\mathrm{n}_{\mathrm{f}}\right)^{1 / 4}$, Where $\mathrm{n}_{\mathrm{f}}=$ number of factorial runs. The axiel points used in suggested design were; $(0,-1),(-1,0),(1,0),(0,1)$ So, the distance of axiel points from center is $\alpha=(4)^{1 / 4}=1$. Generally $\left(3 \leq \mathrm{n}_{\mathrm{c}} \leq 5\right)$ center runs are required to provide stable variance of predicted response. In suggested experiment, 4 axial and 4 central points were added and fitted the second degree model and estimate all of the parameters and second order polynomial equation was obtained from the model (Eq. 1).

$Y=\beta_{0}+\beta_{1} X_{1}+\beta_{2} X_{2}+\beta_{12} X_{1} X_{2}+\beta_{1} X_{1}^{2}+\beta_{2} X_{2}^{2}+\epsilon$

Where $\beta_{0}, \beta_{1}$ and $\beta_{2}$ are representing the overall average, dye concentration and $\mathrm{H}_{2} \mathrm{O}_{2}$ percentage, respectively and level (coded and natural) selected for variables (dye concentration and $\mathrm{H}_{2} \mathrm{O}_{2}$ percentage) are shown in table 1 .

Table 1: Experimental matrix of the variables (coded and natural), with corresponding experimental observed and predicted responses to optimize dye degradation.

\begin{tabular}{|c|c|c|c|c|c|c|c|c|}
\hline \multirow[t]{2}{*}{ Run } & \multirow{2}{*}{$\begin{array}{c}\mathrm{D}(\mathrm{ppm}) \\
\text { Level }^{*}\end{array}$} & \multirow{2}{*}{$\begin{array}{l}\mathrm{H}_{2} \mathrm{O}_{2}(\%) \\
\text { Level** }\end{array}$} & \multicolumn{2}{|c|}{ D removal $(\%)$} & \multicolumn{2}{|c|}{$\mathrm{DO}(\mathrm{mg} / \mathrm{L})$} & \multicolumn{2}{|c|}{$\mathrm{pH}$} \\
\hline & & & $\mathrm{O}$ & $\mathrm{P}$ & $\mathrm{O}$ & $\mathrm{P}$ & $\mathrm{O}$ & $\mathrm{P}$ \\
\hline 1 & $50(-1)$ & $0.05(-1)$ & 40 & 38 & 4 & 3.44 & 6.98 & 7.22 \\
\hline 2 & $100(0)$ & $0.05(-1)$ & 55 & 61 & 4.5 & 5.71 & 6.93 & 6.46 \\
\hline 3 & $150(1)$ & $0.05(-1)$ & 30 & 26 & 3.5 & 2.84 & 7.05 & 7.27 \\
\hline 4 & $50(-1)$ & $3(0)$ & 60 & 68 & 5 & 6.29 & 6.9 & 6.41 \\
\hline 5 & $100(0)$ & $3(0)$ & 96.5 & 91.83 & 9.5 & 8.6 & 5.5 & 5.67 \\
\hline 6 & $150(1)$ & $3(0)$ & 45 & 57.33 & 4.3 & 5.77 & 6.96 & 6.5 \\
\hline 7 & $50(-1)$ & $5.95(1)$ & 35 & 28.66 & 3.75 & 3.01 & 7.02 & 7.26 \\
\hline 8 & $100(0)$ & $5.95(1)$ & 38 & 52.66 & 3.8 & 5.36 & 7 & 6.53 \\
\hline 9 & $150(1)$ & $5.95(1)$ & 27 & 18.66 & 3.4 & 2.57 & 7.15 & 7.37 \\
\hline 10 & $100(0)$ & $3(0)$ & 98 & 91.83 & 9.4 & 8.6 & 5.4 & 5.67 \\
\hline 11 & $100(0)$ & $3(0)$ & 97 & 91.83 & 9.2 & 8.6 & 5.37 & 5.67 \\
\hline 12 & $100(0)$ & $3(0)$ & 96.5 & 91.83 & 9.08 & 8.6 & 5.47 & 5.67 \\
\hline
\end{tabular}

\subsection{Irradiation process}

The model compound (methyl blue) was of analytical grade and purchased from Merck. The radiation source was UV lamp (44 Watt, $254 \mathrm{~nm}$, Pakistan Scientic, Pakistan), protected by a quartz tube. Temperature range of UV system was from $32{ }^{0} \mathrm{C}$ to $40{ }^{\circ} \mathrm{C}$. The dye solution was projected at the bottom of the reactor $(20 \mathrm{~cm}$ from the UV source) and irradiated for $45 \mathrm{~min}$. the concentration of dye in solution was measured spectrophotomerically (Cecil, 7200), while DO 
and $\mathrm{pH}$ values were measured using $\mathrm{pH}$ and DO meters (Lovibond). The dye solutions (50-150 mg/L) were prepared immediately before irradiation using deionized water [10].

III. Statistical analysis

The data manipulated using R, Statistical Software (version 2.13) for ANOVA and predicted value, response surface diagrams, model selection and calculation of stationary points. The effect of variable and their interaction were calculated at $95 \%$ confidence interval of mean.

\section{Results and discussion}

\subsection{Degradation}

The optimization process was carried out using $\mathrm{H}_{2} \mathrm{O}_{2} / \mathrm{UV}$ photocatalytic system for methyl blue degradation in order to evaluate the effect of the system. Tables 1 shows the coded experimental variables, the order in which the experiments were run and number of experiments. In addition, the corresponding observed and predicted responses for the optimization of methyl blue degradation and treatment effect on $\mathrm{pH}$ and DO are also shown in same table 1 . Based on the difference between observed and predicted responses, the model determined the experimental error with a $95 \%$ confidence interval of mean. After generation of experimental matrices with their respective responses, the experimental variables were combined to construct the three-dimensional surface plots. In these plots the synergism between the experimental variables can be observed, resulting in an optimal zone, where it is possible to identify the values of the variables given by the model for optimal response (dye degradation). The response surface of methyl blue (Fig. 2) indicates that the optimal $\mathrm{H}_{2} \mathrm{O}_{2}$ concentration for the efficient removal of dye was $3 \%$ for $100 \mathrm{ppm}$ of dye concentration. Furthermore, DO was found directly related to the dye degradation, while the $\mathrm{pH}$ of the medium decreases by increased degradation. The average ratio of degradation/DO and degradation/pH was found to be 10.19 (increase) and 9.88 (decrease), respectively. The maximum DO value was observed at 96.5 percent degradation and the same medium showed the lowest value of $\mathrm{pH}$ (5.67) (Fig. 3-4).

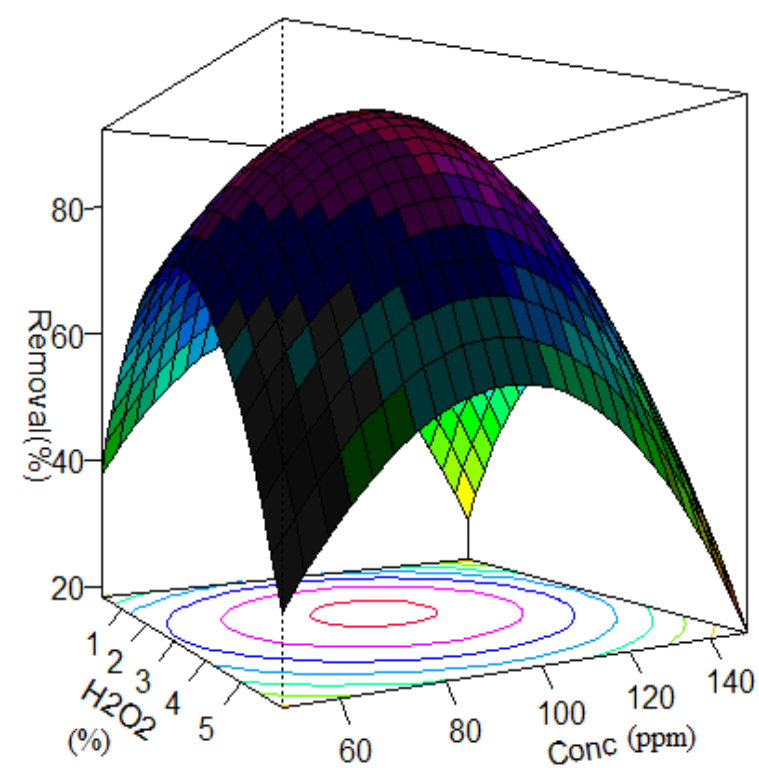

Fig 2: Response surface for the experimental design for dye degradation 


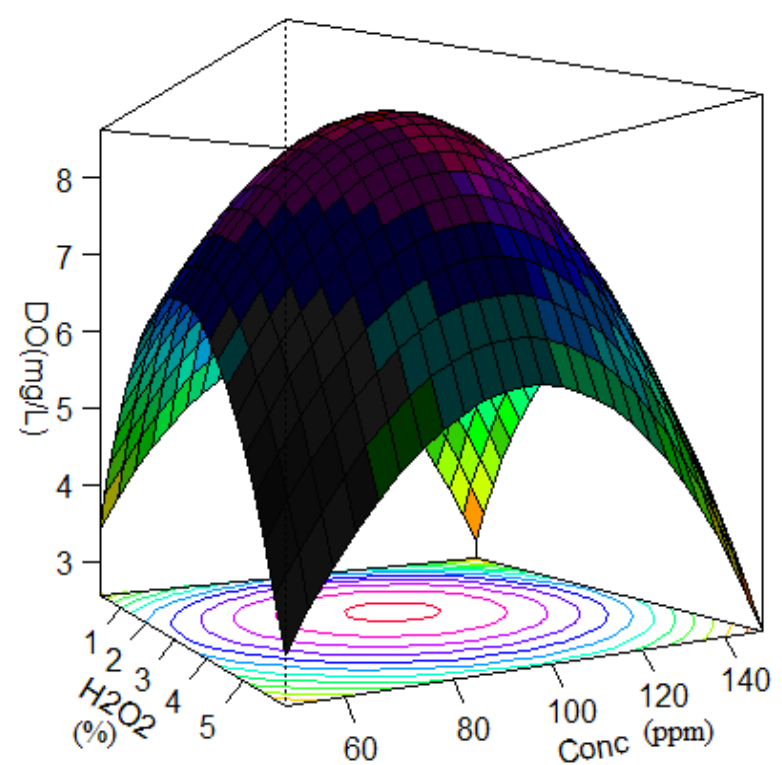

Fig 3: Response surface for the experimental design for dissolved oxygen variation

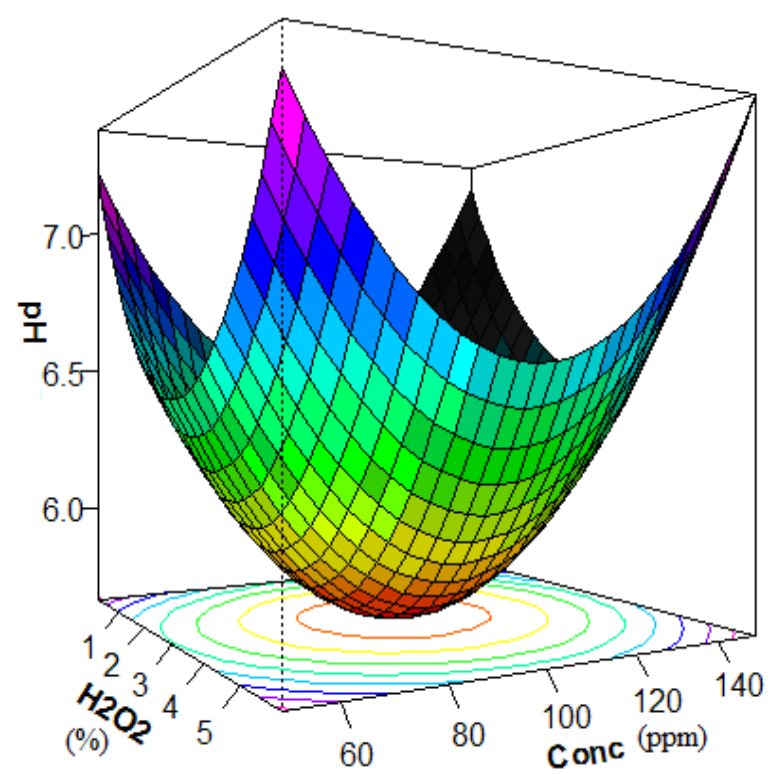

Fig 4: Response surface for the experimental design for $\mathrm{pH}$ variation

By solving statistically the experimental matrix, the polynomial modeling equations were developed, each giving rise to the response surface. The model equations were developed so that the importance of the parameters in the mathematical solution was obtained from the experimental design, with respect to the weight of each variable. Thus, an empirical relationship between the response and the variables was expressed by the polynomial equation; response surface for degradation (Eq. 2), Do (Eq. 3) and pH (Eq. 4), respectively, where $Y, X_{1}$ and $X_{2}$ are representing the response, initial dye concentration and $\mathrm{H}_{2} \mathrm{O}_{2}$ percentage, respectively.

$\mathrm{Y}(\%)$ degradation $=-44.10( \pm 27.07)+2.19( \pm 0.55) \mathrm{X}_{1}+22.37( \pm 6.08) \mathrm{X}_{2}-0.011( \pm 0.002) \mathrm{X}_{1}^{2}-4.02( \pm 0.7) \mathrm{X}_{2}^{2+} \epsilon$

$\mathrm{Y}(\%) \mathrm{DO}=-4.06( \pm 3.48)+0.19(0.07) \mathrm{X}_{1}+2.02(0.78) \mathrm{X}_{2}+0.001(0.0003) \mathrm{X}_{1}^{2}-0.35(0.09) \mathrm{X}_{2}^{2}+\epsilon$

$\mathrm{Y}(\%) \mathrm{pH}=9.59( \pm 1.17)-0.6(0.02) \mathrm{X}_{1}-0.56(0.26) \mathrm{X}_{2}+0.0003(0.0001) \mathrm{X}_{1}^{2}+0.09(0.03) \mathrm{X}_{2}^{2}+\epsilon$

Statistical analyses showed that that the quadratic effects of variables were significant in the response, where the polynomial equation represented the response influenced by combined effect of variables; dye initial concentration and $\mathrm{H}_{2} \mathrm{O}_{2}$ percentage. Fig. 4 shows the influence of each variable on the response and the correlation coefficient values (percentage) for the statistics, with a $95 \%$ confidence interval of mean. In the case of dye degradation and variation in DO, the efficiency of variation was directly influenced by the $\mathrm{H}_{2} \mathrm{O}_{2}$ concentration, while the change in pH was 
influenced by the combined effect of dye initial concentration as well as $\mathrm{H}_{2} \mathrm{O}_{2}$ percentage. The second degree terms were found non significant for measured parameters and $\mathrm{H}_{2} \mathrm{O}_{2}$ was found more effective as compared to dye initial concentration (Fig. 5). All models (dye degradation, $\mathrm{pH}$ and $\mathrm{DO}$ variation) were statistically evaluated as valid, given the values of $\mathrm{R}^{2}$ and $\mathrm{R}^{2}$ adjusted (adj) as; 0.92 and 0.86 for dye degradation, 0.85 and 0.72 for DO change and 0.80 and 0.63 for $\mathrm{pH}$ variation (Table 2). These values of $\mathrm{R}^{2}$ and $\mathrm{R}^{2}$ adj indicate that the regression model provides a good description of the relationship between the independent variables and the responses because $\mathrm{R}^{2}$ represents the fraction of the variation of the response explained by the model and evaluate the statistical validity of the quadratic model with $\mathrm{p}$ $<0.001$.
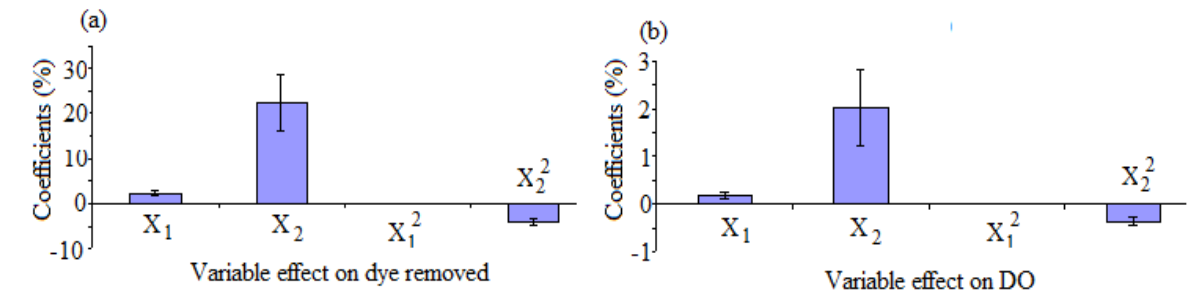

(c)

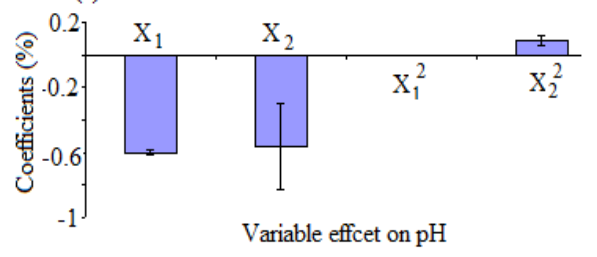

Fig 5: Analysis of the influence of parameters on dye degradation, $\mathrm{DO}$ and $\mathrm{pH}$ with a $95 \%$ confidence interval

ANOVA (Table 2) shows that the fitted model (second order) is not appropriate, since only PQ (Pure Quaderatic) was significant. In other words, it is not meaningful if we will not include first order (FO) terms and only include significant PQ terms. So, the model given above was appropriate since we have included FO terms as well as PQ terms. So, we have used RCCD for optimization of variable and to get maximum response (degradation) using $\mathrm{UV} / \mathrm{H}_{2} \mathrm{O}_{2}$ system.

Table 2: Analysis of variance (ANOVA) for response surface model

\begin{tabular}{cccccc}
\multicolumn{5}{c}{ Table 2: Analysis of variance (ANOVA) for response surface model } \\
\hline SOV & DF & SS & MS & $F$ value & $P$ value \\
\hline Removal (\%) & 2 & 285.7 & 142.8 & 1.20 & 0.36 \\
FO & 1 & 1.0 & 1.0 & 0.008 & 0.92 \\
TWI & 2 & 8228.0 & 4114.0 & 34.74 & $0.0005^{*}$ \\
PQ & 6 & 110.5 & 118.4 & & \\
Residual & 3 & 309.0 & 236.3 & 472.66 & 0.0001 \\
Lack of fit & 3 & 1.5 & 0.5 & & \\
Pure Error & 2 & & & & \\
DO (mg/L) & 1 & 0.58 & 0.29 & 0.14 & 0.8 \\
FO & 2 & 63.70 & 0.006 & 0.002 & 0.9 \\
TWI & 6 & 11.74 & 31.85 & 16.26 & $0.003^{*}$ \\
PQ & 3 & 11.64 & 3.9 & & \\
Residual & 3 & 0.1 & 0.036 & 107.5 & 0.001 \\
Lack of fit & & & & & \\
Pure Error & 2 & 0.01 & 0.009 & 0.04 & 0.95 \\
pH & 1 & 0.0009 & 0.0009 & 0.004 & 0.95 \\
FO & 2 & 5.21 & 2.60 & 11.70 & $0.008^{*}$ \\
TWI & 6 & 1.33 & 0.22 & & \\
PQ & 3 & 1.32 & 0.44 & 121.64 & 0.001 \\
Residual & 3 & 0.1 & 0.03 & & \\
Lack of fit & 3 & & & \\
Pure Error & & & & & \\
\hline
\end{tabular}

* significant effect, $\mathrm{FO}=$ first order, TWI = two way interaction and $\mathrm{PQ}=$ pure quadratic,

$\mathrm{R} 2$ and $\mathrm{R} 2$ adjusted (adj); 0.92 and 0.86 (dye degradation),

R2 and R2 adjusted (adj); 0.85 and 0.72 (DO change)

$\mathrm{R} 2$ and $\mathrm{R} 2$ adjusted (adj); 0.80 and 0.63 (pH variation) 


\subsection{Photochemical process and mechanism}

The optimal conditions observed for the removal of methyl blue dye from aqueous solution by $\mathrm{UV} / \mathrm{H}_{2} \mathrm{O}_{2}$ system was experimentally verified following the kinetic study of the degradation (Fig. 6). The methyl blue degradation followed the first order kinetics with a rate constant of $0.33 \mathrm{~min}^{-1}$. Chemically, the $\mathrm{H}_{2} \mathrm{O}_{2}$ activated by UV light during the photolysis process, generated in situ hydroxyl radicals $\left(\mathrm{OH}^{*}\right)$, which are a highly reactive species responsible for the oxidation process. Analysis of the kinetics showed a rapid decrease in concentration dye treated photocatalytically, resulting in more than $97 \%$ removal after $100 \mathrm{~min}$ of treatment. The main mechanism of AOPs function is the generation of highly reactive free radicals. The $\mathrm{HO}^{\circ}$ are very effective in destroying organic compound because they are reactive electrophiles that react rapidly and non-selectively with nearly all electron-rich organic compounds with a oxidation potential of $2.33 \mathrm{~V}$ and exhibit faster rates of oxidation reactions comparing to conventional oxidants. Once generated, the hydroxyl radicals can attack organic chemicals by radical addition (Eq. 5), hydrogen abstraction (Eq. 6) and electron transfer (Eq. 7) [19, 21-24]. In the following reactions, $\mathrm{R}$ is used to describe the dye molecule.

$$
\begin{aligned}
& R+\mathrm{OH}^{\mathrm{o}} \rightarrow \mathrm{ROH} \\
& R+\mathrm{OH}^{\mathrm{o}} \rightarrow \mathrm{R}^{\mathrm{o}}+\mathrm{H}_{2} \mathrm{O} \\
& \mathrm{R}^{n}+\mathrm{OH}^{\mathrm{o}} \rightarrow \mathrm{R}^{n-1}+\mathrm{OH}
\end{aligned}
$$

The $\mathrm{UV} / \mathrm{H}_{2} \mathrm{O}_{2}$ process has been widely used for dyes removal and results obtained are in accordance with previous studies. Daneshvar et al [25] reported that the $\mathrm{H}_{2} \mathrm{O}_{2}$ concentration up to 2 mmol L ${ }^{-1}$ is effect for dye degradation and Rezaee et al [26] used this process for decolorization of dye and the effects of operating parameters such as $\mathrm{H}_{2} \mathrm{O}_{2}$ dosage, initial dye concentration, $\mathrm{pH}$ and UV dose were evaluated and found that the dye solution was completely decolorized under optimal $\mathrm{H}_{2} \mathrm{O}_{2}$ dosage $\left(2.5 \mathrm{mmol} \mathrm{l}^{-1}\right)$ and low-pressure mercury UV-C lamps (55 w) in less than 30 min. The decolorization rate increased linearly with UV dosage and nonlinearly with increasing initial $\mathrm{H}_{2} \mathrm{O}_{2}$ concentration. According to Yeber et al [27] the dye molecule has a strong tendency toward electron, due to presence of electronegative atom in their structures. Due to high electronegativity, these are attacked by hydroxyl radicals through nucleophilic addition, increasing the nitrate and nitrite and other ions in the solution during the oxidation process as a mineralized product. The methyl blue dye has complex molecular structure that contains nitrogen atoms which on photolysis generates nitrites and nitrates ions and might be responsible for enhanced degradation. The AOPs have appeared as interesting techniques for the treatment of organic pollutants [12, 28-30]. Among the most used is the wellknown $\mathrm{UV} / \mathrm{H}_{2} \mathrm{O}_{2}$ which allows the generation of highly reactive free hydroxyl radicals from the hydroxide ions of water [31-34]. In this study, it was possible to observe that the hydroxyl radicals generated in situ which are responsible for mineralization of methyl blue in the form of nitrate and nitrite ions as well as mineralized carbon. The efficiency of the developed process lies primarily in oxidizing agent strength of the hydroxyl radicals that are formed. On the other hand, the use of multivariate analysis allowed an accurate optimal response and an adequate statistical analysis to obtain the optimal response [7, 20,35].

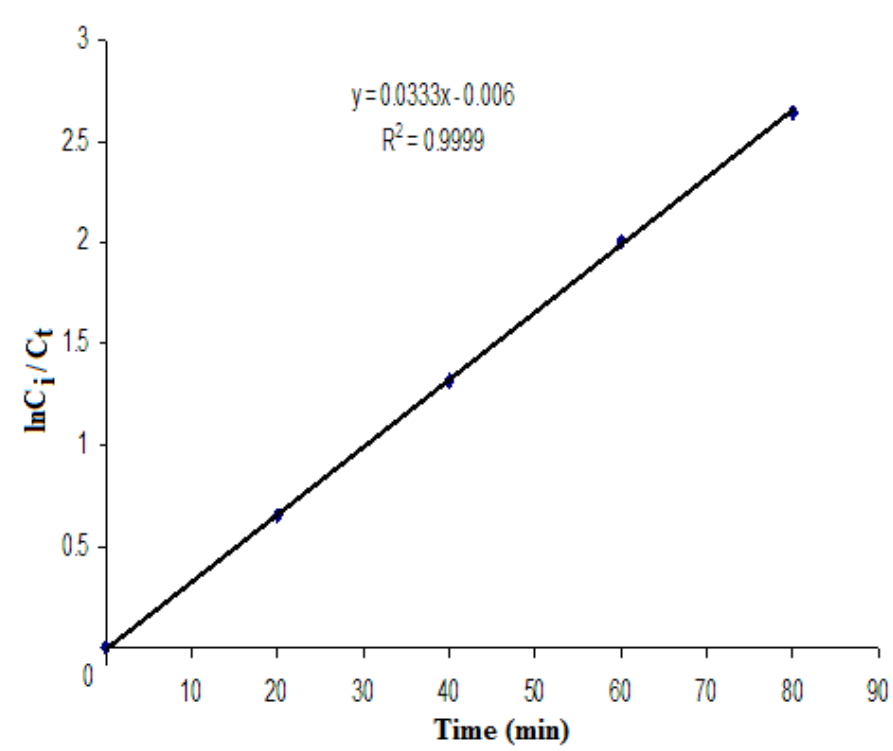

Fig 6: Methyl blue kinetics using the optimized $\mathrm{H}_{2} \mathrm{O}_{2}$ percentage 


\section{Conclusions}

The advanced oxidation process using the $\mathrm{H}_{2} \mathrm{O}_{2} / \mathrm{UV}$ system is an efficient method for degradation of methyl blue. The in situ production of hydroxyl radicals cause faster dye reduction with rate constant $0.33 \mathrm{~min}^{-1}$ following first order of kinetics degradation. The variation in $\mathrm{pH}$ and $\mathrm{DO}$ was found to be dependent on dye degradation. The use of experimental design demonstrates that this is an efficient tool for determining the efficiency of treatments with a statistically reliable analysis.

\section{Acknowledgements}

The authors wish to thank the Higher Education Commission (HEC) of Pakistan for financial support (201346/R\&D/HEC/09/5892).

\section{References}

[1] M. Yucesoy, N. Esen, N. Yulug, Use of chromogenic tube and methyl blue-Sabouraud agar for the identification of Candida Albicans strains Kobe, J. Med. Sci. 2001, vol. 47, pp. 161-167.

[2] M. Hassan, Mohammed D. AlAhmadi, Majid Mosaid, Micellar effect on the kinetics of oxidation of methyl blue by Ce(IV) in sulfuric acid medium. Arabian J. Chem., 2011, in press.

[3] V. Kumar, M. Rahman, N. Khatoon, M. Kumar, Kinetic study of application of various photo catalysts, Der. Pharma Chemica., 2010, vol. 2, pp. 38-45.

[4] Z.T. Yu, Z.L. Liao, Y.S. Jiang, G.H. Li, G.D. Li, J.S. Chen, Construction of a microporous inorganic-organic hybrid compound with uranyl units, Chem. Comun., 2004, pp. 1814-1815.

[5] H. Kusic, N. Koprivanac, L. Srsan, Azo dye degradation using Fenton type processes assisted by UV irradiation: A kinetic study, J. Photochem. Photobiol. A., 2006, vol. 181, pp. 195-202.

[6] C. Gomes da Silva, J. Luis Faria, Photochemical and photocatalytic degradation of an azo dye in aqueous solution by UV irradiation, J. Photochem. Photobiol. A., 2003, vol. 155, pp. 133-143.

[7] N.B. Parilti, C.S.U. Demirel, M. Bekbolet, Response surface methodological approach for the assessment of the photocatalytic degradation of NOM, J. Photochem. Photobiol. A., 2011, vol. 225, pp. 26-35.

[8] D. Prato-Garcia, G. Buitrón, Degradation of azo dye mixtures through sequential hybrid systems: Evaluation of three advanced oxidation processes for the pre-treatment stage, J. Photochem. Photobiol. A., 2011, vol. 223, pp. 103-110.

[9] G. Plantard, F. Correia, V. Goetz. Kinetic and efficiency of TiO2-coated on foam or tissue and TiO2-suspension in a photocatalytic reactor applied to the degradation of the 2,4-dichlorophenol. J. Photochem. Photobiol. A., 2011, vol. 222, pp. 111-116.

[10] Muneer, M., 1.A. Bhatti, E. Haq, M. safdar, F. Rehman, Applications of advanced oxidation process for industrial wastewater treatment. Asian J. Chem., 2010, vol. 22, pp. 3087-3093.

[11] C.A. Martínez-Huitle, E. Brillas, Decontamination of wastewater containing synthetic organic dyes by electrochemical methods: a general review, Appl. Cata. B: Environ., 2009, vol. 87, pp. 105-145.

[12] A. Kumar, P. Kumar, S. Chand, Catalytic wet peroxide oxidation of azo dye (Congo Red) using modified Y zeolite as catalyst, J. Haz. Mat., 2009, vol. 166, pp. 342-347.

[13] C. Lizama, M.C. Yeber, J. Freer, J. Baeza, H. Mansilla, Reactive dye decoloration by TiO2 photo-assisted catalysis, Water Sci. Technol., 2001, vol. 44, pp. 197-203.

[14] S. Parra, S. Malato, C. Pulgarin, New integrated photocatalytic biological flow system using supported TiO2 and fixed bacteria for the mineralization of isoproturon, Appl. Cata. B Environ., 2002, vol. 36, pp. 131-144.

[15] W. Gernjak, T. Glaser, S. Malato, J. Caceres, R. Bauer, A. Fernandez, Photo-Fenton treatment of water containing natural phenolic pollutants, Chemosphere., 2003, vol. 50, pp. 71-78.

[16] J. Saien, M. Asgari, A.R. Soleymani, N. Taghavinia, Photocatalytic decomposition of Direct Red 16 and kinetics analysis in a conic body packed bed reactor with nanostructure titania rasching rings, Chem. Engine. J., 2009, vol. 151, pp. 295-301.

[17] A. Chiaviola, Textiles, Water Environ. Res., 2009, vol. 81, pp. 1696-1730.

[18] D. Georgiou, P. Melidis, A. Aivasidis, K. Gimouhopoulos, Degradation of azo-reactive dyes by ultraviolet radiation in the presence of hydrogen peroxide, Dyes and Pigments., 2002, vol. 52, pp. 69-78.

[19] A.S. Stasinakis, Use Of selected advanced oxidation Processes (AOPs) For wastewater treatment-A mini Review, Global NEST J., 2008, vol. 10, pp. 376-385.

[20] J. Fu, Y. Zhao, Q. Wu, Optimizing photoelectrocatalytic oxidation of fulvic acid using response surface methodology, J. Haz. Mat., 2007, vol. 144, pp. 499-505.

[21] M. Wang, R.Yang, W. Wang, Z. Shen, S. Bian, Z. Zhu, Radiat. Phys. Chem., 2006, vol. 75, pp. $286-291$.

[22] S. Chou, Y.H. Huang, S.N. Lee, G.H. Huang, C. Huang. Treatment of high strength hexamine-containing wastewater by electro-fenton Method. Wat. Res., 1999, vol. 33, pp. 751-759.

[23] D. Georgiou, P. Melidis, A. Aivasidis, K. Gimouhopoulos, Degradation of azo-reactive dyes by ultraviolet radiation in the presence of hydrogen peroxide, Dyes and Pigments., vol. 52, pp. 69-78.

[24] P.R. Gogate, A.B. Pandit, Sonophotocatalytic reactors for wastewater treatment: A critical review, AIChE J., 2004, vol. 50, pp. 1051-1079.

[25] N. Daneshvar, S. Aber, F. Hosseinzadeh, Study of C.I. acid orange 7 removal in contaminated water by photo oxidation processes, Global NEST J., 2008, vol. 10, pp. 16-23.

[26] A. Rezaee, M.T. Ghaneian, S.J. Hashemian, G. Moussavi, A. Khavanin, G. Ghanizadeh, Decolorization of reactive blue 19 dye from textile wastewater by the UV/H2O2 process, J. Appl. Sci., 2008, vol. 8, pp. 1108-1122. 
[27] M.C. Yeber, L. Díaz, J. Fernández. Catalytic activity of the SO4•- radical for photodegradation of the azo dye Cibacron Brilliant Yellow 3 and 3,4-dichlorophenol: Optimization by application of response surface methodology, J. Photochem. Photobiol. A., 2010, vol. 215, pp. 90-95.

[28] M. Cheng, W. Song, W. Ma, Ch. Chen, J. Zhao, J. Lin, H. Zhu, Catalytic activity of iron species in layered clays photodegradation of organic dyes under visible irradiation, Appl. Cata. B: Environ., 2008, vol. 77, pp. 355-363.

[29] B. Ahmed, H. Mohamed, E. Limem, B. Nasr, Degradation and mineralization of organic pollutants contained in actual pulp and paper mill wastewater by a UV/H2O2 process, Industrial \& Engine. Chem. Res., 2009, vol, 48, pp. 3370-3379.

[30] S. Su, S.X. Lu, W.G. Xu, Photocatalytic degradation of reactive brilliant blue X-BR in aqueous solutions using quantum-sized ZnO, Mat. Res. Bull., 2008, vol. 43, pp. 2172-2178.

[31] I. Bouzaida, C. Ferronato, J.M. Chovelon, M.E. Rammah, J.M. Herrmann, Heterogeneous photocatalytic degradation of the anthraquinonic dye, Acid Blue 25 (AB25): a kinetic approach, J. Photochem. Photobiol. A., 2004, vol. 168, pp. 23-30

[32] N. Stock, J. Peller, K. Vinodgopal, P. Kamat, Combinative sonolysis and photocatalysis for textile dye degradation, Environ, Sci. Technol., 2000, vol. 34, pp. 1747-1750.

[33] N. Mahmoodi, M. Arami, N. Limaee, N. Tabrizi, Decolorization and aromatic ring degradation kinetics of Direct Red 80 by UV oxidation in the presence of hydrogen peroxide utilizing TiO2 as a photocatalyst, Chem Engine. J., 2005, vol. 112, pp. 191-196.

[34] R. Matta, K. Hanna, S. Chiron, Oxidation of phenol by green rust and hydrogen peroxide at neutral pH, Separat. Purificat. Technol., 2008, vol. 61, pp. 442-446.

[35] M.D. Sleiman, D. Vildozo, C. Ferronato, J.M. Chovelon, Photocatalytic degradation of azo dye Metanil Yellow: optimization and kinetic modelling using a chemometric approach, Appl. Cata. B: Environ., 2007, vol. 77, pp. 1-11. 